\title{
Chapter 4 \\ Choosing Products for Decentralized \\ Manufacturing: Utilizing Recycled 3D \\ Printing Filament in India and Germany
}

\author{
Lennart Büth $\mathbb{D}^{\mathbb{D}}$, Max Juraschek $(\mathbb{D}$, Sebastian Thiede, \\ and Christoph Herrmann 1
}

\begin{abstract}
As additive manufacturing technologies become widely available as desktop 3D printers, opportunities for decentralized manufacturing arise. The goal of the 3-CYCLE project is to produce plastic filament for 3D printing by recycling waste plastics and thus moving towards sustainable decentralized manufacturing. Leading to the question which product should be produced within the paradigm of sustainable distributed manufacturing using 3D printing with locally recycled filament. Therefore, this work proposes a framework to rate potential products regarding fabrication with recycled filament. A hierarchical criteria-system is developed covering important properties and constraints linked to the 3-CYCLE process and its characteristics. A weighting process to assign different importance levels to the proposed criteria-system by experts is created. Subsequently, a decision-making process is developed to rank in accordance of the assessed alternatives to the criteria-system. The multi-attribute process includes decision-making techniques (TOPSIS, WSM and WPM), an aggregation step and a verification approach. In a case study, ten products are compared with the developed approach. Resulting into four different rankings, differentiating between India, Germany and the inclusion of educational aspects.
\end{abstract}

Keywords 3D printing $\cdot$ Multi-criteria decision making $\cdot$ Recycled filament

\subsection{Introduction}

Plastic has become an essential part of daily life. The global production has increased by $500 \%$ over the last 30 years and will continue to grow to 850 million tons by 2050 (Shen et al. 2009). This trend is resulting in increasing environmental issues as for instance land (Rees 1980) and water (Derraik 2002) pollution rises. The project

\footnotetext{
L. Büth $(\varangle) \cdot$ M. Juraschek $\cdot$ S. Thiede $\cdot$ C. Herrmann Chair of Sustainable Manufacturing and Life Cycle Engineering, Institute of Machine Tools and Production Technology (IWF), Technische Universität Braunschweig, Langer Kamp 19b, 38106 Braunschweig, Germany

e-mail: 1.bueth@tu-braunschweig.de
} 
3-CYCLE (the project name refers to the goal to recycle plastic material with 3Dprinting) was established between the universities TU Braunschweig and Birla Institute of Technology and Science (BITS) Pilani to address the presented problems by utilizing the current open source development of fused deposition modelling (FDM). The Institute of Machine Tools and Production Technology of the TU Braunschweig designed an integrated plastic recycling process for the FDM 3D printing technology. This process is researched under the following constraints, which also serve as input for this work: The process should be resilient, be easy to perform and be transferable to an economical usage in a small, distributed scale. The deployment of this process in different settings and countries should have economic value and raise awareness of recycling possibilities and the recycling necessity of plastics. In cooperation with the Indian university BITS Pilani, this process is in development. Furthermore, the outcome should also be used in educational purposes as part of lectures and/or student projects (Juraschek et al. 2017).

This work addresses the later stage of the 3-CYCLE project. After the technical and the organizational processes were designed, the most effective utilization of this project has to be determined. Therefore, this work develops a methodological approach to rate potential outcomes of the introduced 3-CYCLE process. Starting with the produced filament as input material, the process should take a variety of criteria and boundary conditions into consideration. As a special requirement the work tries to include regional characteristics from India and Germany, as well as educational value of product ideas. With the result is a multi-criteria decision making (MCDM) methodology that is able to compare different ideas for this specified filament usage.

\subsection{Criteria-System Definition}

The requirements for the criteria-system as background for the rating methodology are defined by the goals of the 3-CYCLE project as stated in Chap. 1. To ensure a structured decision making process and to ensure the applicability of the criteriasystem, formal and structural requirements need to be fulfilled:

Structured in a Hierarchy. The criteria-system should be structured in a hierarchy. On the one hand, a hierarchical system provides a clear structure. On the other hand, with a hierarchical order, the subsequent weighting process can be accomplished in incremental steps. Without a hierarchical structure, the weighting process has to compare heterogeneous information, e.g. specified (second-tier) economically criteria to specified social criteria. Resulting in potentially flawed results. Such a hierarchical criteria-system is e.g. proposed by Mendoza and Macoun (1999).

Formulated as Verifiers. All selected criteria have to be formulated as verifiers and have to be measurable with available tools, within available capabilities and data. Whenever possible, objective verifiers should be preferred over subjectively rated verifiers. 
Addressing Feasibility. An important requirement is the technical feasibility of the production process of FDM 3-D printing. Limitations and advantages should be considered in a criteria-system. Castillo et al. (2012) including the feasibility into the principle of human-centered design. Besides the feasibility, the viability and the desirability of a product should be addressed. Therefore, the feasibility is defined with the topics of design, technology and innovation, summarized with the question "What is technically possible?". The viability of a product is defined with the question "What can be financially viable?". And the desirability is defined as user context research, with the leading question "What do users desire?" (Kelley et al. 2009).

Addressing Sustainability. Fostering sustainable development, economic, environmental and social impacts of the recycling and production process as well as of the subsequent life cycle phases should be considered. Also included as criteria by (Savonen 2015) for sustainable product design for 3D printing.

Addressing Academia. Lastly, the criteria shall address the need to develop the project close to aca-demia and therefore the product should have an educational value inherent.

Based on the derived requirements a hierarchical criteria-system with three tiers is created as illustrated in Fig. 4.1. The principles are set at the highest tier and consist of human-centered design, sustainability and the conceptual-fit. While the first two principles are self-explanatory, the principle conceptual-fit is a place holder for giving context to the circumstances in which the system is applied. In this work it fulfills the educational context as stated in requirements (5). Following, the criteria tier is clustering the principles to further ensure a more objective weighting process, while consisting of criteria described in the requirements (3-5).

In the lower tier, indicators describe the criteria more specific. Each indicator is operationalized by verifiers for the later decision making process. All indicators/verifiers are stated within Table 4.1. The verifiers are designed heterogeneously, ranging from qualitative scales to measurements in degrees or distances. Qualitative scale ranges are selected due to the granularity of possible alternatives, aiming for linear coherences, a high value is desired. This property results in the requirements for the decision-making process to handle heterogeneously verifiers.

\subsection{Methodological Approach for Multi-criteria Decision Making}

The method developed aims at evaluating possible products with regard to the characteristics of the 3-CYCLE and the developed criteria-system. The approach should be able to weight the heterogeneous verifiers. The process is based on the approach for sustainable decision making presented in Wang et al. (2009). Adopting the procedure and the main elements: Criteria selection (Chap. 2), weighting, multi-criteria decision making and aggregation. The overall approach is summarized in Fig. 4.2. 
a

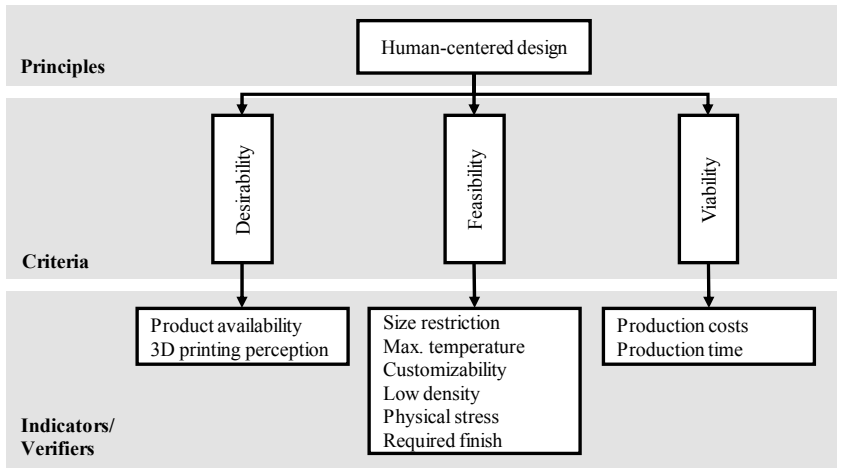

b

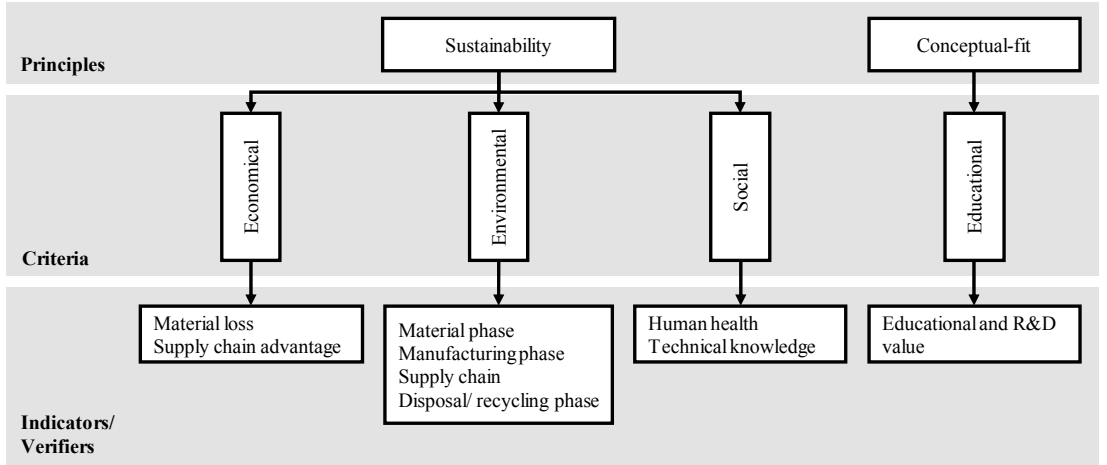

Fig. 4.1 Hierarchical criteria-system, consisting of three tiers: Principles, criteria and indicators/verifiers. a Principle Human-centered design, b principles Sustainability and Conceptual-fit

\subsubsection{Weighting Process Using AHP and Delphi Iterations}

The weighting process for the criteria is combining Analytic Hierarchy Processes (AHP) (Saaty 1988) as well as Delphi iterations (Wang et al. 2009) (see grey area Fig. 4.2). This approach enables the combination of weights created by multiple experts. Within an AHP the relation of two criteria rated by a pairwise comparison resulting in a weighting. Each individual expert starts with an AHP weighting process in seven steps:

1. Introduction of the topic

2. Introduction of the hierarchical criteria-system

3. Specific explanation of the criterion-indicators

4. Successive seven AHPs, indicator level

5. Specific explanation of the criteria of a principle

6. Successive three AHPs, criterion level

7. AHP, principle level. 
Table 4.1 Overview of all indicators, verifiers and the respective measurement scales of all three principles, utilizing heterogeneous scales

\begin{tabular}{|c|c|c|}
\hline Indicator & Verifier & Scale \\
\hline $\begin{array}{l}\text { Product availability on } \\
\text { markets }\end{array}$ & Scale & $0-24$ \\
\hline $\begin{array}{l}\text { Changed perceived value due } \\
\text { 3DP Scale }\end{array}$ & Scale and score & $0-3$ \\
\hline Max. temperature & Temperature & ${ }^{\circ} \mathrm{C}$ \\
\hline Customizability level & Scale & $0-4$ \\
\hline Low density advantage & Scale & $0-2$ \\
\hline Physical stress & Scale and score & $0-12$ \\
\hline Required finish & Decision & Yes/No \\
\hline Production costs & Costs & Euro \\
\hline Production time & Time & Minutes \\
\hline Material loss & Malus matrix & 1,2 \\
\hline Supply chain advantage & Scale & $0-3$ \\
\hline Impact in raw material phase & $\mathrm{CO}_{2} \mathrm{Eq}$. & Difference \\
\hline Impact in manufacturing phase & $\mathrm{CO}_{2} \mathrm{Eq}$. & Difference \\
\hline $\begin{array}{l}\text { Impact in recycling/deposal } \\
\text { phase }\end{array}$ & $\mathrm{CO}_{2} \mathrm{Eq}$ & Difference \\
\hline Impact in supply chain & Scale & $0-3$ \\
\hline $\begin{array}{l}\text { Human health, due to } \\
\text { post-processing }\end{array}$ & Decision & Yes/No \\
\hline $\begin{array}{l}\text { Requirement technical } \\
\text { knowledge }\end{array}$ & Scale & $0-2$ \\
\hline Educational and $R \& D$ value & Scale & $0-2$ \\
\hline
\end{tabular}

After conducting initial AHPs with multiple experts, Delphi iterations follow. Therefore, the resulting weightings of all experts are aggregated to a merged weighting. Then the individual experts are exposed to the merged weighting. The individual experts can revisit their weighting with regard to the merged weighting, resulting in a second iteration of individual AHP results. In a final step these results are aggregated to the final criteria-weighting.

\subsubsection{Multi-attribute Decision Making}

In the next step, the product alternatives are rated according to the criteria-system applying the verifiers. After values are assigned, the data is normalized and thereby prepared for the MCDM techniques.

Many different MCDM methods are available in the literature. The subset of MCDM suitable for the decision problem of this work is called multi-attribute decision making (MADM), as the criteria are attributes of the set products. Different 


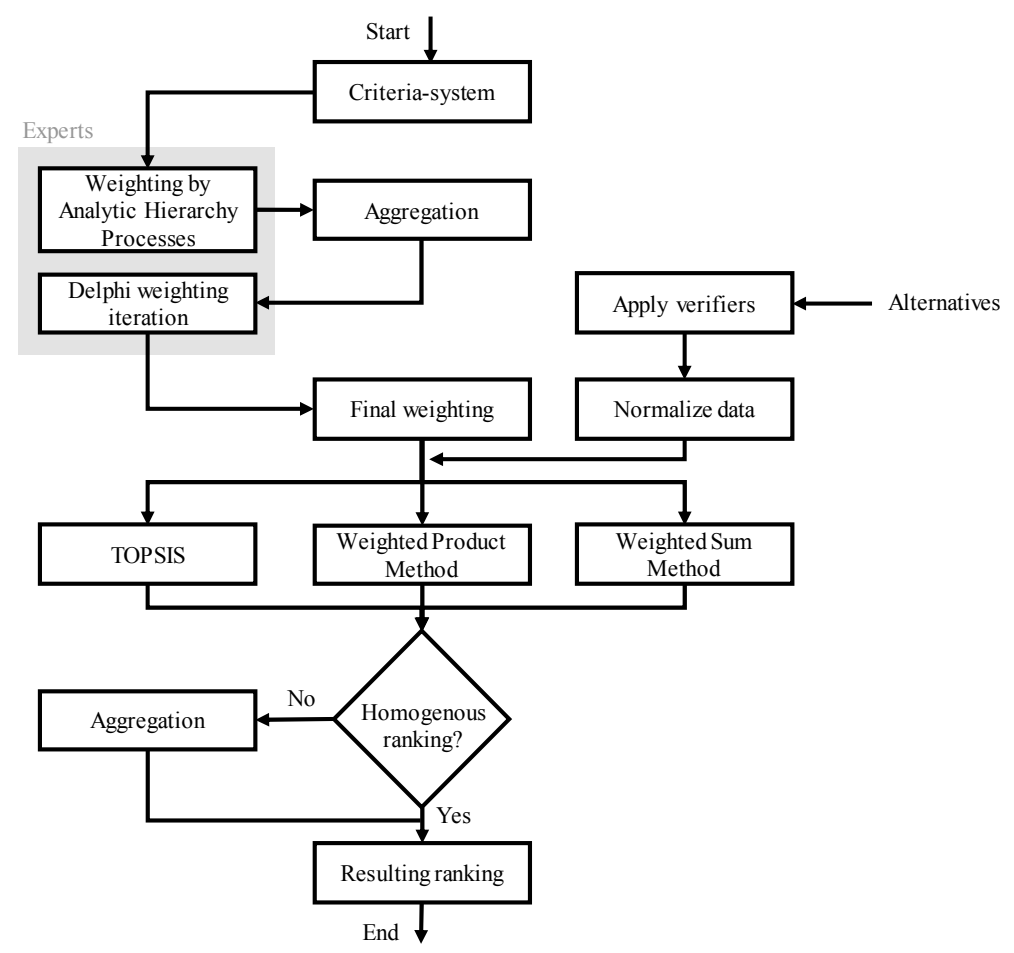

Fig. 4.2 Overview of the developed methodological approach for MADM using the developed criteria-system

MADM approaches are used in literature and no clear advantages on one or the other can be found. Therefore, a literature review was conducted on similar decision problems. Appling the three most used MADM methods for product selection: Technique for Order Preference by Similarity to Ideal Solution (TOPSIS), Weighted Product Method (WPM) and Weighted Sum Method (WSM). These techniques are executed in the next step, with the input of the normalized data and the weights. The resulting rankings are then compared and if necessary aggregated.

To ensure all crucial parts are considered in the decision-making process, the developed process is compared to the generalized approach for sustainable decision making from WANG et al. (2009). All steps before the beginning of the weighting procedure are covered. The loop starting with "Checking the concordance of criteria values", seem to be different, but is similar to the Delphi iteration process. Instead of increasing the number of experts, the experts can reevaluate their weights. Proceeding, WANG et al. determine objective weights, and check these for concordance/integrate them. As previously discussed, a decision between subjective and objective weighting (e.g. equal weights) was done. Therefore, this loop was not adopted in the developed process. The aggregation loop of WANG et al. matches the present aggregation procedure. To conclude, all crucial elements were considered, 
only the objective weighting loop is missing out. If necessary such a loop could be integrated, when improving the approach.

\subsection{Case Study: What to Use Recycled Plastic Filament for?}

In a case study ten different 3D printable products were exemplary compared using the developed approach summarized in Fig. 4.2. The following 3D printable products were ranked: Calipers, a wardrobe wall adapter, a hand prosthesis, a phone case, a bracelet, a soap case, a robot arm kinematic, a tape gun, a whistle and an ear bud holder. The approach was applied for four different rakings: Usage in India and Germany with as well as without the principle conceptual-fit. The results are visualized in Fig. 4.3, "1" being the best ranked and "10" the worst.

Exemplary the rating of the product alternative "Bracelet" for the criterion feasibility is stated: Build size restriction is the first feasibility verifier, the bracelet fits on all printers building platform and is therefore assigned with the value " 2 ". The temperature limits of PET are not exceeded in the using phase of a bracelet; thus the verifier temperature is rated with "No". The customizability level scale is rated with " 2 ", as the outer appearance of the bracelet is its key feature and potentially total customizable. Regarding the verifier low density advantage, the value " 0 " is assigned. A bracelet has a relatively thin design, and can therefore not utilize the low density advantage of 3D printing. The verifier physical stress is rated with a "9". In the subcategories the stress categories tension, flexural, fatigue and wear stress, got rated with the maximum value " 2 ". A bracelet, as an everyday wearing device, is strongly exposed to these kinds of physical stress. The category compression stress

Fig. 4.3 Aggregated MADM results, comparing ten products in four different ratings

\begin{tabular}{|c|c|c|c|c|c|}
\hline & \multicolumn{4}{|c|}{ Rating } \\
\hline & & India & Germany & $\begin{array}{c}\text { India incl. } \\
\text { Conceptual-fit }\end{array}$ & $\begin{array}{l}\text { Germany incl. } \\
\text { Conceptual-fit }\end{array}$ \\
\hline \multirow{10}{*}{ 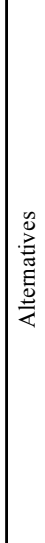 } & Calipers & 5 & 3 & 3 & 2 \\
\hline & Wardrobe & 5 & 6 & 10 & 10 \\
\hline & Prothesis & 2 & 10 & 1 & 8 \\
\hline & Phone Case & 7 & 4 & 8 & 7 \\
\hline & Bracelet & 1 & 1 & 2 & 1 \\
\hline & Soap Case & 3 & 4 & 4 & 6 \\
\hline & Kinematic & 10 & 9 & 4 & 3 \\
\hline & Tape Gun & 9 & 7 & 7 & 3 \\
\hline & Whistle & 3 & 2 & 6 & 3 \\
\hline & Bud holder & 8 & 7 & 9 & 9 \\
\hline
\end{tabular}


is rated with " 1 ", as compression stress can occur during handling process but only limited in the intended use case. The category impact stress was assigned with the value " 2 ", as no physical impact should occur in an intended using scenario. The last feasibility verifier required finish was rated with "No". No finish is mandatory for the bracelet to fulfill its application.

The final results over all normalized criteria of the aggregated MADM methods are stated in Fig. 4.3. Some alternatives are homogenous rated between all four iterations (e.g. the alternatives ear bud holder and bracelet). Some alternatives clearly state the difference between the regions and between the inclusion and exclusion of the conceptual-fit principle.

The alternative wardrobe is clearly showing the effect of the included conceptualfit. Due to the relatively bad rating in this high weighted verifier, the wardrobe is ranked 10 for both regions. In contrast the robot arm kinematic is relatively better ranked due to the high impact of good ratings in the added principle. The alternative hand prosthesis is indicating the differences between both regions, most likely due to the impact of two verifiers measuring impact and advantage of the supply chain. Additionally, the verifiers production costs (e.g. differentiating energy costs) and product availability are contributing to the differences between India and Germany.

\subsection{Discussion and Conclusions}

A decision making approach for potential 3-CYCLE products was developed and applied in a case study. The weighting process was successfully conducted. The second weighting iteration yielded only minor changes to the first round results, this might be reasoned due to the relatively homogenous expert group. The feedback of the experts regarding the hierarchical system design was positive. Sometimes it was difficult for the experts to remember the definitions of the introduced criteria/indicators while conducting the AHPs. Assigning values to the alternative/indicator combination was unproblematic. Only the price of the prosthesis had to be assumed. Some of the introduced scales were easy to rate (e.g. Yes/No verifiers), some scales are relying on assumptions. The designed MADM process is mainly relying on subjective opinions, as is the criteria-system. Therefore, an improvement regarding this coherence may be necessary in future. Although the case study proves that the developed approach fulfills all requirements of the problem. The case study provided an initial insight in the application of the developed method, the results give a first orientation for the 3-CYCLE project. 


\section{References}

Shen L, Haufe J, Patel M (2009) Product overview and market projection of emerging bio-based plastics PRO-BIP 2009. Report for European polysaccharide network of excellence (EPNOE) and European bioplastics 243

Rees J (1980) The fate of carbon compounds in the landfill disposal of organic matter. J Chem Technol Biotechnol. https://doi.org/10.1002/jctb.503300121

Derraik JG (2002) The pollution of the marine environment by plastic debris: a review. Mar Pollut Bull 44(9):842-852. https://doi.org/10.1016/S0025-326X(02)00220-5

Juraschek M, Cerdas F, Posselt G, Herrmann C (2017) Experiencing closed loop manufacturing in a learning environment. Procedia Manuf 9:57-64. https://doi.org/10.1016/j.promfg.2017.04.046

Mendoza G, Macoun P (1999) Guidelines for applying multi-criteria analysis to the assessment of criteria and indicators. The criteria $\&$ indicators toolbox series, 60 , center for international forestry research. https://doi.org/10.17528/cifor/000769

Castillo LG, Diehl JC, Brezet JC (2012) Design considerations for base of the pyramid (BoP) projects. In: Proceedings of the cumulus helsinki 2012 conference, pp 1-15. https://doi.org/10. $1145 / 1865245.1865255$

Kelley D, Moggridge B, Nuttall M (2009) Design kit: the field guide to human-centered design

Savonen BL (2015) Criteria for sustainable product design with 3D printing in the developing world, Technical report Michigan Technological University

Wang JJ, Jing YY, Zhang CF, Zhao JH (2009) Review on multi-criteria decision analysis aid in sustainable energy decision-making. Renew Sustain Energy Rev 13(9):2263-2278. https://doi. org/10.1016/j.rser.2009.06.021

Saaty TL (1988) What is the analytic hierarchy process? mathematical models for decision support. Springer, Heidelberg, pp 109-121. https://doi.org/10.1007/978-3-642-83555-1_5

Open Access This chapter is licensed under the terms of the Creative Commons Attribution 4.0 International License (http://creativecommons.org/licenses/by/4.0/), which permits use, sharing, adaptation, distribution and reproduction in any medium or format, as long as you give appropriate credit to the original author(s) and the source, provide a link to the Creative Commons license and indicate if changes were made.

The images or other third party material in this chapter are included in the chapter's Creative Commons license, unless indicated otherwise in a credit line to the material. If material is not included in the chapter's Creative Commons license and your intended use is not permitted by statutory regulation or exceeds the permitted use, you will need to obtain permission directly from the copyright holder.

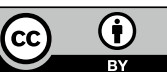

